\title{
Mandibular-Lingual Repositioning Device - MLRD: preliminary results of 8 patients with Obstructive Sleep Apnea Syndrome - OSAS
}

\author{
College of Dentistry of the Universidade de São Paulo (USP), Center for Sleep Studies of the Hospital das Clinicas \\ of the USP Medical School, and the Center for Sleep Disorders at the Hospital Israelita Albert Einstein, \\ and the Baptista Silva Clinica - São Paulo, Brazil
}

\begin{abstract}
Dental devices have been employed in the treatment of snoring and obstructive sleep apnea syndrome (OSAS) of mild to moderate degrees. The authors disclose the preliminary results in 8 patients with clinically diagnosed obstructive sleep apnea polisomnographically confirmed and treated with a dental device (Mandibular-Lingual Repositioning Device - MLRD) developed by one of the authors (RCB). Cephalometrics was performed before usage of MLRD, Epworth Sleepiness Scale (ESS) tests were conducted before and after the MLRD and a questionnaire that subjectively qualified the Overall Subjective Improvement of the patient (OSI) was filled out. The tests were repeated 4 weeks after the application of the MLRD. The average subjective overall improvement was $73.75 \%$ and the Epworth Sleepiness Scale was 13.88 (pre - MLRD) and 6.63 (post - MLRD) representing a significant statistical variation ( $p=0.05$ ). The authors discuss probable factors involved in the improvement of the subjective measurements of excessive sleepiness.
\end{abstract}

UNITERMS: Obstructive Sleep Apnea. Snoring. Dental device.

\section{INTRODUCTION}

$\mathrm{O}$ bstructive Sleep Apnea Syndrome (OSAS) is an incapacitating condition with a high rate of morbidity and mortality. Various prevalence studies estimate that 1 to $8.5 \%$ of the male adult population between 45 and 65 years old show signs of clinically relevant obstructive sleep apnea syndrome. The combination of cranio-mandibular-facial alterations (disproportional anatomy) with a structural alignment of

\section{Address for correspondence:}

Ricardo Castro Barbosa

Rua Divino Salvador

São Paulo, SP - Brasil - CEP 04078 - 010 the upper airways (UA) associated primarily with obesity and neuro-muscular functional factors are elements that are etiologically responsible for the collapse of the upper airway in the obstructive sleep apnea syndrome.

The nasal "CPAP" (continuous positive airway pressure) is the first choice of therapy for the treatment of obstructive sleep apnea syndrome primarily for moderate and severe cases. However term adherence to nCPAP is of $58 \%$ in patients with slight to moderate OSAS, and $89 \%$ in severe cases of obstructive sleep apnea syndrome. Other therapeutic alternatives generally used simultaneously, include: behavioral changes (weight loss, abstinence from alcohol, lateral decubitus), mechanical devices (dental device), medication (anti-depressants, medroxiprogesterone, theophilyne), surgery (uvulopalatopharingoplasty, mandibular protrusion, tracheostomy, etc.) in obstructive different combinations. 
In recent years the use of dental device in the treatment of obstructive sleep apnea syndrome and primary snoring have received growing attention primarily due to its acceptance, low morbidity of treatment and relative efficiency in treatment of mild to moderate cases $(2,4,5,6,7,8,12,23,24,36,38)$. The first reported use of dental device for expansion of the upper airways was performed on Robin (34) in 1902 and subsequently in 1921 and 1923 on children with cranial-facial dismorphia. In 1934 Robin (34) described another type of one-piece device that pushed the mandible and tongue forward so as to increase the size of the upper airways.

There are 2 difficulties concerning the use of "nCPAP" in our country: its high cost and problems with tolerance, making the use of dental device viable primarily because of its low cost, non-invasiveness, reversibility and wide acceptance. In this article we will report the preliminary results of subjective procedures of 8 patients treated with the Mandibular-Lingual Repositioning Device - MLRD, developed by one of the authors (RCB). The MLRD is a intra oral rigid unibody type Device, removable, used during sleep with the purpose of mandibular repositioning (figure 4).

\section{METHODS}

Eight patients clinically and polisomnographically diagnosed as having mild obstructive sleep apnea syndrome were studied. Six were male, ages between 45 and 55 years old (average 51.25) and an average body mass of $27.64 \mathrm{~kg} / \mathrm{m}^{2}$.
All of the patients underwent a polysomnographic study for definitive diagnoses. Radiological tests were also performed consisting of cephalometric teleradiography taken in three positions, central occlusion, end to end of the incisor and maximum mandibular extension. Recommendations for weight loss, abstinence from alcohol, use of sedatives and improvement in posture were made to all of the patients associated with the use of the Mandibular-Lingual Repositioning Device. The Mandibular-Lingual Repositioning Device was individually adjusted for each patient. The evaluation of the subjective parameters were made by :

1. The Epworth Sleepiness Scale (ESS) (17) was applied before and after the placement of the MandibularLingual Repositioning Device. The Epworth Sleepiness Scale consists of eight questions answered by the patient with regards to daily activities measured on a scale of zero to three and having proportionate values of starting from a minimum of zero to a maximum of twenty four points (appendix 1).

2. Questionnaire for measuring Overall Subjective Improvement (OSI) post-Mandibular-Lingual Repositioning Device. This questionnaire consisted of two questions and was answered in the form of percentages. The results for each patient were a percentage average of both questions which were the following:

A) How much did your physical and mental disposition improve upon awakening?

B) How much did your physical and mental disposition improve throughout the day?

The tests were repeated 4 weeks after the final adjustments were made to the Mandibular-Lingual Repositioning Device and the results then submitted to statistical analysis (Student's "t" test).

Table I

Patients general data

\begin{tabular}{llccccccc}
\hline Patient & Sex & RDI pre & Sat $_{2}$ & ESS pre & ESS post & BMI & OSI & Weight var. \\
\hline 1 & $\mathrm{~F}$ & 46.7 & 90.0 & 7.0 & 4.0 & 26.53 & $70.00 \%$ & +1 \\
2 & $\mathrm{M}$ & 30.1 & 96.0 & 23.0 & 11.0 & 29.47 & $70.00 \%$ & +0 \\
3 & $\mathrm{M}$ & 45.2 & 71.0 & 20.0 & 12.0 & 27.60 & $80.00 \%$ & +0 \\
4 & $\mathrm{M}$ & 55.0 & 92.0 & 12.0 & 4.0 & 27.09 & $70.00 \%$ & +0 \\
5 & $\mathrm{M}$ & 58.0 & 82.0 & 7.0 & 4.0 & 27.11 & $80.00 \%$ & -2 \\
6 & $\mathrm{M}$ & 23.1 & 75.0 & 17.0 & 10.0 & 26.10 & $90.00 \%$ & -3 \\
7 & $\mathrm{~F}$ & 11.0 & 83.0 & 18.0 & 5.0 & 26.03 & $95.00 \%$ & +0 \\
8 & $\mathrm{M}$ & 55.5 & 80.0 & 7.0 & 3.0 & 31.00 & $75.00 \%$ & +0 \\
\hline Average & & 40.58 & 83.53 & 13.88 & 6.63 & 27.64 & $76.25 \%$ & -1 \\
D.P. & & 17.25 & 8.57 & 8.47 & 3.70 & 1.75 & $11.57 \%$ & +1 \\
\hline
\end{tabular}


Table 2

Cephalometric readings

\begin{tabular}{lccc}
\hline & \multicolumn{3}{c}{ Milimmiters } \\
\cline { 2 - 4 } Patient & MPH & PAS & PNS-P \\
\hline 1 & 28.6 & 5.2 & 43.2 \\
2 & 14.5 & 12.0 & 41.8 \\
3 & 22.5 & 1.6 & 43.3 \\
4 & 23.4 & 7.2 & 41.1 \\
5 & 22.3 & 12.7 & 49.3 \\
6 & 39.1 & 9.5 & 58.1 \\
7 & 24.7 & 8.0 & 36.3 \\
8 & 40.8 & 5.0 & 40.2 \\
Average & 27.0 & 7.7 & 44.2 \\
D.P. & 8.9 & 3.7 & 6.7 \\
\hline Normal & 15.0 & 11.0 & 37.0 \\
Readings & & & \\
\hline
\end{tabular}

Legend - MPH: distance between the hyoid bone and the mandibular plane; PAS: posterior airway; PNS-P: distance between the posterior nasal spine and the soft palate caudal end.

\section{RESULTS}

The results are presented in Table I.

The polisomnographic tests indicated an average of 40.58 apnea - hypopnea (IAH) events per hour; 29.33 apnea events per hour and an average minimum oxygen saturation of $82.43 \%$.

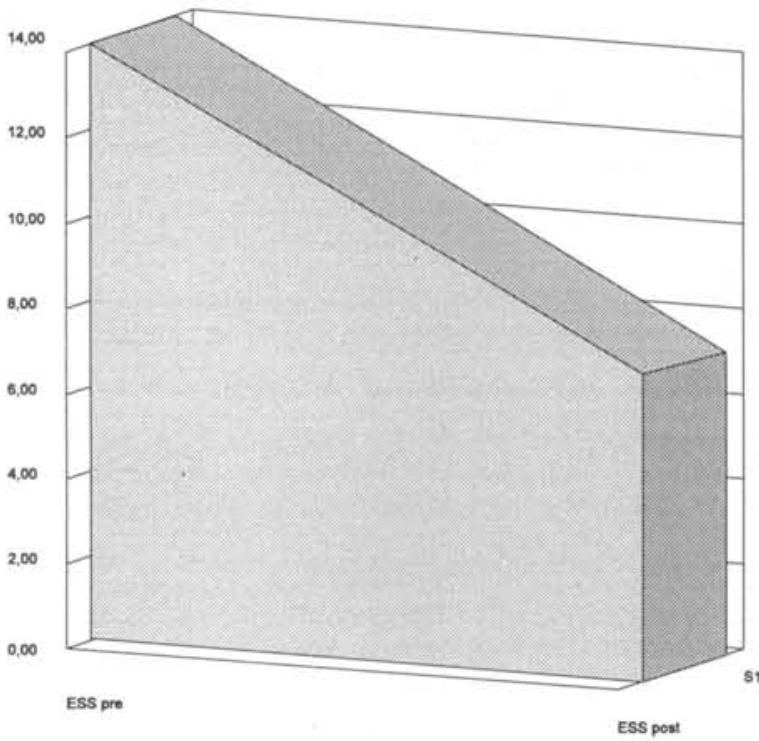

FIGURE1 - Graph representing the variation in excessive daytime sleepiness as measured by the Epworth Sleepiness Scale. Values obtained before and after treatment with the Mandibular-Lingual Repositioning Device
The teleradiography tests showed an average deviation of the posterior aerial space (PAS) of $-3.35 \mathrm{~mm}$; of the distance between the hyoid bone and the mandibular plane (MPH) of $11.96 \mathrm{~mm}$, and of the average length of the soft palate (PNS-P) of $7.16 \mathrm{~mm}$. These results are presented in detail in Table II.

The ESS scores obtained pre- and post- treatment (13.88 and 6.63) respectively showed a statistically significant difference $(\mathrm{p}=0.05)$ and that is shown in figure 1 .

The Overall Subjective Improvement (OSI) 76.25\% improvement. All patients showed increased salivation immediately after the application of the MandibularLingual Repositioning. Device, becoming normal approximately after 30 days of use. There were no signs of temporomandibular joint discomfort related to the device.

\section{DISCUSSION}

The preliminary results of this study showed a statistically significant improvement in daytime sleepiness as measured by ESS. There was also an overall subjective improvement after the initial use of the MandibularLingual Repositioning Device.

The Epworth sleepiness scale is recognized as valid for the quantification of the general level of excessive daytime sleepiness (17). It differentiates normal individuals from those with sleep disorders of various pathological afflictions. The values obtained positively correlated with the multiple sleep latencies test (33), independent of pathology (17). Values above 5.9102 .2 are indicators of excessive sleepiness (17). Patients with obstructive sleep apnea syndrome recorded values that statistically correlated with incidence of apnea-hipopnea and with a minimum saturation of oxygen obtained in the polisomnography (17). The initial weight recorded was obtained during the polisomnographic diagnosis and after insertion, adjustment and control of the Mandibular-Lingual Repositioning Device. A slight weight variation was observed in only two of the patients; patient no. 1 gained $1 \mathrm{~kg}$ and patient no. 2 lost $3 \mathrm{~kg}$ during the evaluation period.

Patients with obstructive sleep apnea syndrome display anatomic narrowing of the upper airways. usually the narrowing is specifically located in the palatopharyngeal segment. Obesity, in addition to soft tissues, is the principal cause of the narrowing of the upper airways. Craniofacial dismorphias contribute to a lesser extent. Lowe et al. revealed in a study using computerized 


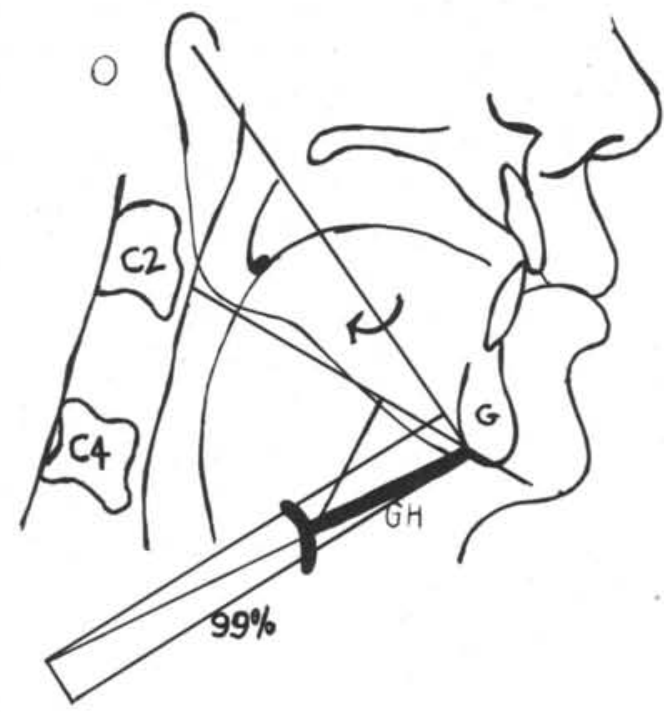

FIGURE 2 - Schematic Diagram showing the position of the hyoid bone in a patient diagnosed as having obstructive sleep apnea syndrome. MP-H is the perpendicular distance from the mandibular plane to the hyoid bone. The mandibular plane is the distance between the gonion point of the mandible angle to the point of gnathion in the menton. In patients with obstructive sleep apnea syndrome, this distance is always increased in comparison with normal individuals. The hyoid bone is found below and posterior in patients with obstructive sleep apnea syndrome.

three dimensional CT, an increase of $27.6 \%$ the volume of the upper airways, specifically in the oropharynx region with the application of dental devices. It is important to note that the increased size to the upper airway decreased their collapsibility during inhaling (negative pressure).

Patients having obstructive sleep apnea syndrome, the hyoid bone is located below the mandibular plane. The

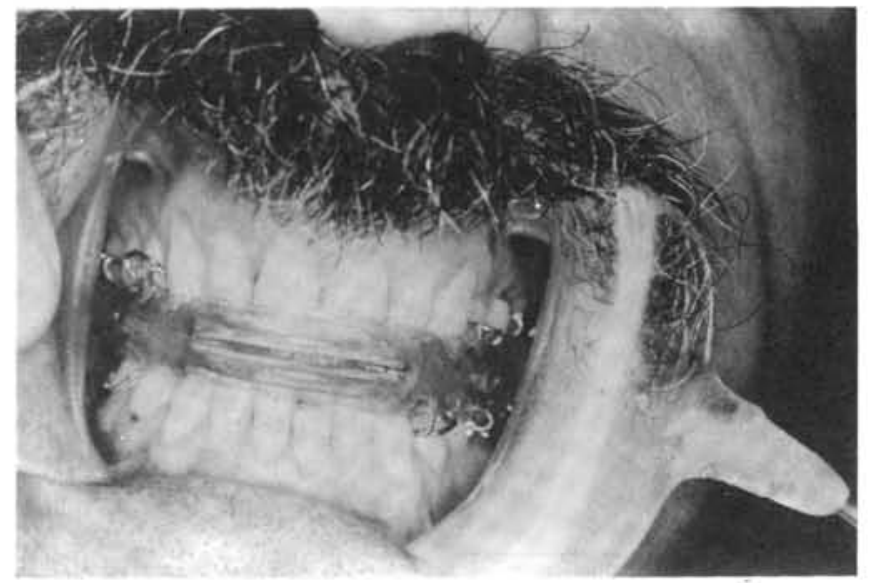

FIGURE 4 - Photograph of the Mandibular-Lingual Repositioning Device applied to the mouth.

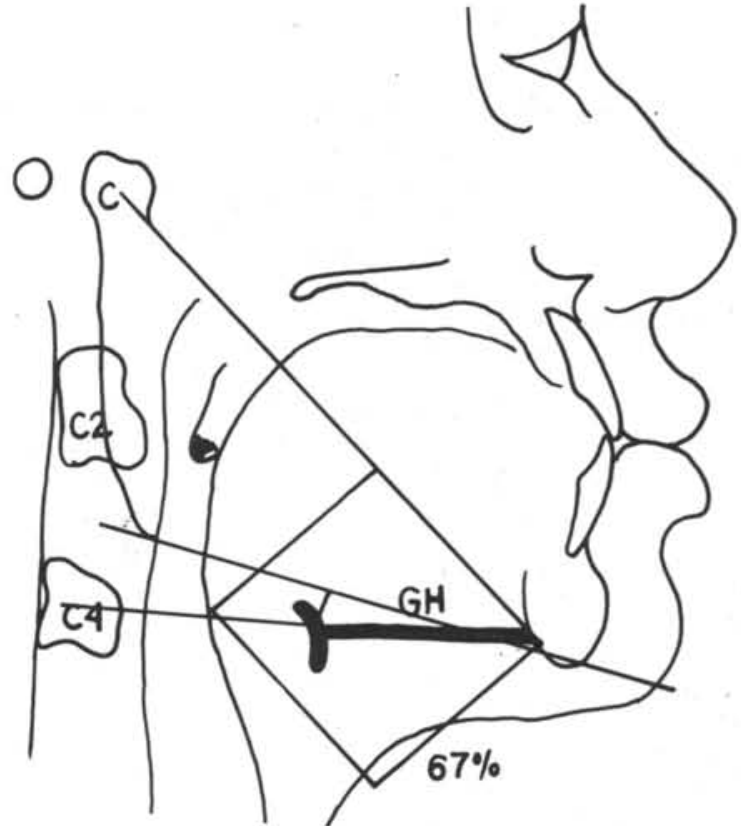

FIGURE 3 - Schematic Diagram of the hyoid bone in an individual diagnosed with obstructive sleep apnea syndrome. MP-H is the perpendicular distance from the mandibular plane to the hyoid bone. The mandibular plane is the distance between the gonion point of the mandibular angle to the point of gnathion in the menton. In normal individuals, the MP-H distance is less than in patients with OSAS.

forward dislocation and positioning of the mandible caused by the use of the Mandibular-Lingual Repositioning Device allows the geniohyoid muscle to function more efficiently in the dilation of the upper airway. When the hyoid bone is situated below as in the case of obstructive sleep apnea syndrome, the contraction of the geniohyoid muscle generates a force vector that for the most part contributes to the opening of the mandible (figure 2). When the hyoid bone is situated higher in relation to the mandibular plane, the geniohyoid exerts a forward tension on the hyoid bone, thereby dilating the upper airways (figure 3). The mandibular positioning achieved by the Mandibular-Lingual Repositioning Device in patients with obstructive sleep apnea syndrome, with an increase of the MP-H dimension, allows the geniohyod muscle to exert a forward tension vector on the hyoid bone, consequently dilating the upper airway passages without opening the mouth. The position of the mandible has a profound influence on the muscular activity of the tongue, as was demonstrated in animal experiments. Rotation of the lower mandibular increases tonic basal genioglossal muscular activity. The inferior rotation of the mandible and the proprioceptive stimulation of the tongue caused by the Mandibular-Lingual Repositioning Device can most 
probably cause increased activity in the tonic basal genioglossal muscular activity and consequently lessen the collapse of anterior wall of the oropharynx.

\section{CONCLUSIONS}

1) The subjective measurement of daytime sleepiness (ESS) showed a statistically significant improvement with the use of the Mandibular-Lingual Repositioning Device in this group of patients with obstructive sleep apnea syndrome.

2) Objective polysomnographic data should be studied to confirm the effectiveness of the MandibularLingual Repositioning Device therapy.

\section{Epworth Sleepiness Scale}

Name Age

Weight Date $\operatorname{Sex}() F() M$

Diagnosis

Occupation $\mathrm{AHI}$

Medication

What is the probability of your "napping" or falling asleep in the following situations, (not to be confused with simply feeling tired)? This is in reference to your current routine lifestyle. Even if you haven't necessarily experienced one of these situations try to answer how the situation might affect you.

$0=$ no possibility of napping

$2=$ moderate possibility of napping

$1=$ low possibility of napping

$3=$ good possibility of napping

Situation

Possibility of Napping

Sitting and reading

Watching TV

Sitting in a public place

As a passenger on a train, bus or car, having been

traveling for more than an hour

When circumstances permit; laying down to rest during the afternoon

Sitting and talking with someone

Sitting calmly after a lunch with no alcoholic consumption

In heavy traffic for a few minutes; if you have a car

TOTAL 


\section{ReSUMO}

Introdução: Os apareilhos bucais têm sido usados principalmente para o tratamento de roncos primários e síndrome da apnéia obstrutiva do sono (SĀOS) leve-moderada. Os autores relatam resultados clínicos preliminares em 8 pacientes com sindrome da apnéia obstrutiva do sono diagnosticada clínica e polissonograficamente. Foram tratados com o Aparelho Reposicionador Mandibulo-Lingual (ARML), desenvolvido por um dos autores (RCB). Material e Métodos: Foram realizados: cefalometria pré-ARML; escala de sonolência de Epworth (ESE) pré e pós-ARML e questionário que quantifica uma melhora global subjetiva (MGS) do paciente. Controles foram obtidos 4 semanas pós-ARML. Resultados: A melhora global subjetiva foi de $73,75 \%$ em média e a escala de sonolência de Epwoeth variou de 13,88 (pré-ARML) para 6,63 (pósARML) apresentando significância estatística $(p=0,05)$. Os autores discutem os prováveis fatores envolvidos na melhora da medida subjetiva de sonolência excessiva diurna.

\section{REFERENCES}

1. BERNSTEIN, A. \& REIDY, R. - The effects of mandibular repositioning on obstructive sleep apnea. J. Craniomandibular Practice 6: 179-181, 1988.

2. BONHAM, E.; CURRIER, G.; ORR, W.; OTHMAN, J. \& NANDA, R. - The effects of a modified functional appliance on OSA. Am. J. Orth Dentofac Orthop 94: 384-392, 1988.

3. BRADLEY, T.; BROWN, I.G.; GROSSMAN, R.F.;ZAMEL, N.; MARTINEZ, D.; PHILLIPSON, E.A. \& HOFFSTEIN, V.- Pharyngeal size in snorers, nonsnoreres, and patients with Obstructive Sleep Apnea. New Engl. J. Med. 315: $1327-$ 1327, 1986.

4. CARTWRIGHT, R.D. \& SAMELSON, C.F. - The effects of a nonsurgical treatment for obstructive sleep apnea. Jama 248: 705-709,1982

5. CARTWRIGHT, R.D. - Predicting Response to the Tongue Retaining Device for Sleep Apnea Syndrome. Arch Otolaryngol 111: 385-388, 1985.

6. CARTWRIGHT, R.D.; STEFOSKI, D.\& CALDARELLI, D. - Toward a treatment logic for sleep apnea: the place for the tongue retaining device. Behav Res Ther 26: 121-126., 1988

7. CARTWRIGHT, R.D.; RISTANOVIC, R.; DIAZ, F.; CALDARELLI, D. \& ALDER, G. - A Comparative Study of Treatments for Positional Sleep Apnea. Sleep 14: 546552,1991

8. CLARK, G.T. \& NAKAMO, M. - Dental appliances for the treatment of obstructive sleep apnea. J. Am. Dent Ass 118: 611-619,1989.

9. CRAMPETTE, L.; CARLANDER, B.; MONDAIN, M.; BILLIARD, M.; GUERRIER, B. \& DEJEAM, Y. - Surgical Alternatives to Uvulopalatopharynplasty in Sleep Apnea Syndrome. Sleep 5: S63-S68, 1992.

10. DJUPESLAND, G.; LYBERG, T. \& KROSGTAD, O. Cephalometrics analysis and surgical treatment of patients with obstructive sleep apnea. Acta Otoryngol 103: 551-557, 1987.

11. FUJITA, S.; CONWAY, W.; ZORICK, F. - Surgical correction of antomical abnormalities in Obstructive Sleep Apnea: Uvulopalatopharingoplasty. Otorynol Head Neck Surg 89: $923-934,1981$

12. GEORGE, P. - A modified functional appliance for treatment of obstructive sleep apnea.J Clin Ortho 21: 171-175, 1987.

13. GUILLEMINAULT, C. - Obstructive sleep apnea syndrome. Psych Clin North Am 10: 607-6261, 1987.

14. HE, J.; KRYEGER, M.H.; ZORICK,.F.J.; CONWAY, W. \& ROTH, T. - Mortality and apnea index in obstructive sleep apnea. Chest 94: 9-14, 1988.

15. HORNER, R.L.; MOHIADDIN, R.H.; LOWELL, D.G.; SHEA, S.A.; BURMAN, E.D.; LONGMORE, D.B \& GUZ, A. - Sites and Sizes of fat deposits around the pharynx in obese patients with obstuctive sleep apnea and weight matched controls. Eur Respir J 2: 613-622. 1989.

16. ISSA, F.G \& SULLIVAN, C.E. - Upper airway closure pressures in obstructive sleep apnea. J Appl Physiol 57: 140146. 1984.

17. JOHNS, M.W. - A New Method for Measuring Daytime Sleepiness: The Epworth Sleepiness Scale. Sleep 14:540$545,1991$.

18. KRIEGER, J. - Long - Term Compliance with Nasal Continuos Positive Airway Pressure (CPAP) in Obstrucive Sleep Apnea Patients and Nonapneic Snorers. Sleep 15: S42S46, 1992.

19. KRYGER, M.H. - Management of Obstructive Sleep Apnea. In: Principles and Practice of Sleep Medicine, KRYGER, M.; ROTH, T. \& DEMENT, W. (eds). Saunders, Toronto, 584-590, 1986.

20. KUNA, S.T. \& SANT'AMBROSIO, G. - Pathophysiology of Upper Airway Closure during Sleep. JAMA 22: 1384$1389,1991$. 
21. LOWE, A.; GURZA, S. \& SESSELE, B. - Excitatory and inhibitory influences on tongue muscle activity in cat and monkey. Brain Res 21: 417-422, 1976.

22. LOWE, A.; SANTAMARIA, J.; FLEETHAM, J.\& PRICE, C. - Facial morphology and obstructive sleep apnea. Am J Orthod Dentofac Orthop 90: 364-374, 1986.

23. LOWE, A. - Effects of a mandibular repositioning appliance used in the treatment of obstructive sleep apnea on tongue muscle activity. In: ISSA, F., SURATT, P. \& REMMERS, J. (eds) Sleep and Respiration, New York: Wiley-Liss, Inc. 395-405, 1990.

24. LOWE, A. - Dental appliances for the treatment of snoring and/ or obstructive sleep apnea. In KRYEGER, M.; ROTH, T. \& DEMENTW. (eds) Principles and practice of sleep medicine. 2 nd edition. W.B. Saunders Co: 722-735, 1993.

25. MONTPLAISIR, J..; BÊDARD, M.A.; RICHER, F. \& ROULEAU, I. - Neurobehavioral Manifestations in Obstructive Sleep Apnea Syndrome Before and After Treatment with Continuous Positive Airway Pressure. Sleep 15: S17-S19, 1992.

26. NICO-MURCIA, G.; MCCANN, C.C.; BLIWISE, D.L..; GUILLEMINAULTIC, C. \& DEMENT, W.C. - Compliance and side effects in sleep apnea patientes treated with nasal continuous positive airway pressure. West J. Med. 150: 165 $169,1989$.

27. PARTINEN, M.; GUILLEMINAULT, C.; QUERA-SALVA, M.A. \& JAMIESON, A. - Obstructive Sleep Apnea and cephalometric roentgenograms. The role of anatomic upper airway abnormalities in the definition of abnormal breathing during sleep. Chest 93: 1199-1205, 1988a.

28. PARTINEN, M.; JAMIESON, A. \& GUILLEMINAULT, C. - Long term outcome for obstructive sleep apnea syndrome patients: mortality. Chest 94: 1200-1204, 1988b.

29. PARTINEN, M. \& GUILLEMINAULT, C. - Daytime sleepiness and vascular morbidity at seven-year follow-up in obstructive sleep apnea patients. Chest 97: 27-32, 1990.
30. PARTINEN, M. \& TELAKIVI, T. - Epidemiology of Obstructive Sleep Apnea. Sleep 15: S1-S4, 1992.

31. POWEL, N.B. \& RILEY, R.W. Obstructive sleep apnea, continuous positive airway pressure, and surgery. Otolaryngol Head Neck Surg. 99: 362-369, 1988.

32. REMMERS, J.E. - Anatomy and physiology of upper airway obstruction. In: Principles and Practice of Sleep Medicine, KRYGER, M.; ROTH, T. \& DEMENT, W. (eds). Saunders, Toronto, 525-536, 1989.

33. RICHARDSON, G.S.; CARSKADON, M.A.; FLAGG, W.; VAN DEN HOED, J.; DEMENT, W.C. \& MITTLER M.M. Excessive daytime sleepiness in man: multiple sleep latency measurements in narcoleptic and control subjects. Electroencephalogr Clin Neurophysiol 45: 621-627, 1978.

34. ROBIN, P. - Glossoptosis due to atresia and hyportrophy of the mandible. Amer J. Dis. Child. 48: 541-7, 1934.

35. SANDERS, M.H.; GRUENDL, C. \& ROGERS, R.M. Patient compliance with nasal CPAP therapy for sleep apnea. Chest 90: 330-333, 1986.

36. SCHIMIDT-NOWARA, W.; MEADDE, T. \& HAYS, M. Treatment of snoring and obstructive sleep apnea with a dental orthosis. Chest 99: 1378-1385, 1991.

37. SHEPARD, J.W.; GEFTER, W.B.; GUILLEMINAULT, C.; HOFFMAN, E.A.; HOFFSTEIN, V.; HYDGEL, D.W.; SURATT, P.M. \& WHITE, D.P. - Evaluation of the Upper Airway in Patients with Obstructive Sleep Apnea. Sleep 14: 361-371, 1992.

38. SOLL, B. \& GEORGE, P. - Treatment of obstructive sleep apnea with a nocturnal airway-patency appliance. N. Engl. J. Med. 313: 386, 1985.

39. THURROW, R.C. - Functional anatomy of the dental mechanisms. In: Atlas of Orthodontic Principles. C. V. Mosby Co., St. Louis, 135, 1970.

40. WALDHORN, R.E.; HERRICK, T. W.; NGUYEN, M.C.; O'DONNEL, A.E.; SODERO, J. \& POTOLICCHIO, S.J. Long term compliance with nasal continuous positive airway pressure therapy for sleep apnea. Chest 97: 33-38, 1990. 